Saba H Al-Zubaidi BDS, MSc (Assist Lect)

\section{Effect of Tooth Paste and Mouth Wash on Brackets Dimension}

\author{
Dept of Pedod, Orthod, and Prev Dentistry \\ College of Dentistry, University of Mosul
}

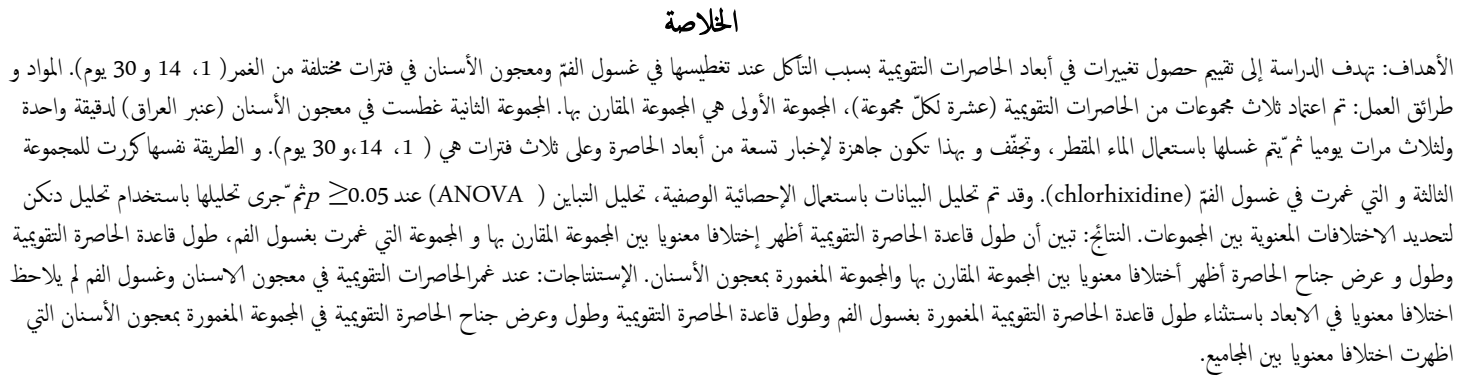

ABSTRACT

Aims: To evaluate whether dimensions of the brackets change due to corrosion when immersed in tooth paste and mouth wash at different intervals of immersion (1, 14 and 30 days). Materials and Methods: Three groups of bracket (ten for each), the first group is the control group. The second group immersed in tooth paste (Anber- Iraq) for one minute three times daily then removed and washed in distill water, dried and be ready for testing nine dimensions of the bracket at three intervals $(1,14$, and 30 days). The same procedure was repeated for the third group that was immersed in mouth wash (chlorhexidine). The data was analyzed using Descriptive statistic, analysis of variance (ANOVA) at $p \leq 0.05$. These data were then analyzed by the Duncan multiple analysis range test to locate the significant differences among the groups. Results: The bracket base length showed a significant difference among the control and the immersed brackets in mouth wash. The bracket base length, wing length and wing width showed a significant differences among the control and the immersed brackets in tooth paste. Conclusions: when immersing the brackets in tooth paste and mouth wash no significant dimensional changes occurred in bracket's dimension except for the bracket base length of the brackets immersed in mouth wash and the bracket base length, wing length and width of brackets immersed in tooth paste that showed significant changes among the groups.

Key words: Bracket dimension, Tooth paste, Mouth wash.

Al-Zubaidi SH. Effect of Tooth Paste and Mouth Wash on Brackets Dimension. Al-Rafidain Dent J. 2010; 10(2): 292-297.

Received: $19 / 4 / 2009$

Sent to Referees: 27/4/2009

Accepted for Publication: 16/6/2009

\section{INTRODUCTION}

Stainless steel alloys are the first and foremost alloys used in the faculty of orthodontics in form of wires, brackets and bands ${ }^{(1)}$. However, the most orthodontic brackets are made of stainless steel containing $8 \%$ to $12 \%$ nickel, $17 \%$ to $22 \%$ chromium and various proportions of manganese, copper, titanium and iron ${ }^{(2,3)}$, with two orthodontic bracket slot sizes $(0.022$ inch and 0.018 inch) are separated by four thousandths of an inch ${ }^{(4)}$.

Corrosion is defined as an electro- chemical or chemical process of complete or partial disintegration or deterioration of a metal due to its reaction with the environment ${ }^{(5)}$.

Fixed appliance mechanics involves stages during which the teeth are moved by sliding brackets along an arch wire ${ }^{(6)}$. These brackets are exposed to the oral cavity, which is a potentially corrosive environment and the release of metallic ions from orthodontic devices is a genuine con$\operatorname{cern}^{(7-10)}$. The oral environment is particularly ideal for the biodegradation of metals 
because of its thermal, microbiologic and enzymatic properties ${ }^{(11)}$. These environmental conditions of the oral cavity might alter the morphological, structural and compositional characteristics, force delivery of arch wire, super elasticity and fracture of orthodontic alloy ${ }^{(12)}$.

Chlorhexidine has been used as an effective adjunct treatment for periodontal disease both as mouth rinse and as one of the ingredients in tooth paste ${ }^{(13)}$.

The aim of this study is to evaluate whether the corrosion produced by using mouth wash and tooth paste affect the bracket dimensions at three interval periods (1 day, 14 day and 30 day).

\section{MATERIALS AND METHODS}

The bracket samples consisted of 30 stainless steel standard edge wise $0.018 \mathrm{x}$ 0.030 inch bracket bicuspid (Dentarum, Germany). The brackets were collected into three groups (10 for each). The first group was used as a control, the second group was immersed in the mouth wash (chlorhexidine) (Al-mansor- Iraq) and the last group were immersed in tooth paste (Anber- Iraq).

Ten brackets were immersed completely in a specific container contained chlorhexidine solution. Then they were withdrawn after one minute (three times daily). The sample removed from the solution and washed with distill water, dried and kept to be ready for testing at interval (1, 14 and 30 days). The same procedure was carried out for the other groups of brackets that were immersed in the tooth paste.

The bracket dimensions included slot width and depth and interwing gap as designed by Hassan ${ }^{(14)}$ were measured under microscope with the lens of microscope degreed in micron then divided into magnification of lens and then all measurements were recorded. Other measurements including labiolingual inclination of slot and bracket base curvature as conducted by Hassan ${ }^{(14)}$ were performed by taking a photographic view at a constant quality and the magnification of microscope (20x) and the lens of digital camera (Genex) were fixed on the eye lens of the microscope. Other measurements were measured by using digital vernia and including: Bracket base length, the longest distance from occlusal aspect to gingival aspect of the bracket base. Bracket width, the widest distance from mesial to distal aspects of the bracket base. Wing width, the distance between the lateral aspect of the mesoocclusal wing and distoocclusal wing. Wing length, the distance between the superior aspects of the mesoocclusal wing to the inferior aspect of the mesogingival wing.

The statistical analysis of the data included descriptive statistic, analysis of variance (ANOVA) the data were initially analyzed using the one-way ANOVA test at $p \leq 0.05$. These data were then analyzed by the Duncan multiple analysis range test to locate the significant differences among the groups.

\section{RESULTS}

Tables (1, and 2) demonstrates the descriptive statistic (mean and standard deviation), ANOVA analysis and Duncan multiple analysis range test of the control brackets and brackets immersed in mouth wash and tooth paste at the three intervals. The bracket base length showed a significant difference among the control and the immersed brackets in mouth wash. The bracket base length, wing length and wing width showed a significant differences among the control and the brackets immersed in tooth paste.

Duncan multiple analysis range test showed that the bracket base length of the bracket's immersed in mouth wash increased significantly than that of control group during the first day and also after two weeks the value increased. Whereas the bracket base length of the brackets immersed in tooth paste increased significantly as compared with control group with increasing the immersion period.

The bracket wing length and width in tooth paste group at first day explored significant difference as compared to the brackets wing length and width of the control one. 
Table (1): Descriptive statistic and ANOVA analysis and Duncan Multiple Analysis Range test for the control group brackets and brackets immersed in mouth wash at three intervals.

\begin{tabular}{|c|c|c|c|c|c|c|}
\hline Variable & Period* & Mean & \pm SD & F-value & Sig. & $\begin{array}{c}\text { Duncan's } \\
\text { group }\end{array}$ \\
\hline \multirow{4}{*}{$\begin{array}{l}\text { Slot width } \\
\quad(\mathrm{mm})\end{array}$} & 0 & 0.46 & 0.000 & \multirow{4}{*}{0.000} & \multirow{4}{*}{1.000} & $\mathrm{~A}$ \\
\hline & 1 & 0.46 & 0.000 & & & A \\
\hline & 2 & 0.46 & 0.000 & & & A \\
\hline & 3 & 0.46 & 0.000 & & & $\mathrm{~A}$ \\
\hline \multirow{4}{*}{$\begin{array}{l}\text { Slot depth } \\
\quad(\mathbf{m m})\end{array}$} & 0 & 0.76 & 0.000 & \multirow{4}{*}{0.000} & \multirow{4}{*}{1.000} & $\mathrm{~A}$ \\
\hline & 1 & 0.76 & 0.000 & & & A \\
\hline & 2 & 0.76 & 0.000 & & & A \\
\hline & 3 & 0.76 & 0.000 & & & A \\
\hline \multirow{4}{*}{$\begin{array}{l}\text { Interwing } \\
\text { gap }(\mathbf{m m})\end{array}$} & 0 & 1.26 & 0.000 & \multirow{4}{*}{0.000} & \multirow{4}{*}{1.000} & $\mathrm{~A}$ \\
\hline & 1 & 1.26 & 0.000 & & & A \\
\hline & 2 & 1.26 & 0.000 & & & A \\
\hline & 3 & 1.26 & 0.000 & & & A \\
\hline \multirow{4}{*}{$\begin{array}{l}\text { Bracket base } \\
\text { length (mm) }\end{array}$} & 0 & 2.79 & 0.000 & \multirow{4}{*}{17.835} & \multirow{4}{*}{$0.000 * *$} & $\mathbf{B}$ \\
\hline & 1 & 2.82 & 0.023 & & & $\mathbf{C}$ \\
\hline & 2 & 2.76 & 0.013 & & & $\mathbf{A}$ \\
\hline & 3 & 2.80 & 0.016 & & & B \\
\hline \multirow{4}{*}{$\begin{array}{l}\text { Bracket base } \\
\text { width }(\mathbf{m m})\end{array}$} & 0 & 3.76 & 0.000 & \multirow{4}{*}{1.802} & \multirow{4}{*}{0.164} & A \\
\hline & 1 & 3.75 & 0.014 & & & A \\
\hline & 2 & 3.65 & 0.228 & & & A \\
\hline & 3 & 3.75 & 0.029 & & & A \\
\hline \multirow{4}{*}{$\begin{array}{l}\text { Wing length } \\
(\mathrm{mm})\end{array}$} & 0 & 3.01 & 0.000 & \multirow{4}{*}{0.451} & \multirow{4}{*}{0.718} & $\mathrm{~A}$ \\
\hline & 1 & 3.07 & 0.186 & & & A \\
\hline & 2 & 3.11 & 0.331 & & & $\mathrm{~A}$ \\
\hline & 3 & 3.08 & 0.194 & & & $\mathrm{~A}$ \\
\hline \multirow{4}{*}{$\begin{array}{l}\text { Wing width } \\
(\mathrm{mm})\end{array}$} & 0 & 3.65 & 0.000 & \multirow{4}{*}{1.613} & \multirow{4}{*}{0.203} & $\mathrm{~A}$ \\
\hline & 1 & 3.59 & 0.179 & & & $\mathrm{~A}$ \\
\hline & 2 & 3.51 & 0.187 & & & $\mathrm{~A}$ \\
\hline & 3 & 3.55 & 0.139 & & & A \\
\hline \multirow{4}{*}{$\begin{array}{l}\text { Bracket base } \\
\text { angle (in de- } \\
\text { gree) }\end{array}$} & 0 & 110.00 & 0.000 & \multirow{4}{*}{0.000} & \multirow{4}{*}{1.000} & $\mathrm{~A}$ \\
\hline & 1 & 110.00 & 0.000 & & & A \\
\hline & 2 & 110.00 & 0.000 & & & $\mathrm{~A}$ \\
\hline & 3 & 110.00 & 0.000 & & & $\mathrm{~A}$ \\
\hline \multirow{4}{*}{$\begin{array}{l}\text { Labiolingual } \\
\text { angle (in de- } \\
\text { gree) }\end{array}$} & 0 & 90.00 & 0.000 & \multirow{4}{*}{0.000} & \multirow{4}{*}{1.000} & $\mathrm{~A}$ \\
\hline & 1 & 90.00 & 0.000 & & & A \\
\hline & 2 & 90.00 & 0.000 & & & A \\
\hline & 3 & 90.00 & 0.000 & & & A \\
\hline
\end{tabular}

$* 0$ control group(10 brackets), 1 first day in mouth wash, 2 two weeks in mouth wash, 3 one month in mouth wash (10 brackets for each period). ${ }^{*}$ Significant at $p \leq 0.05 ; \mathrm{SD}=$ Standard deviation. 
Table (2): Descriptive statistic and ANOVA analysis and Duncan Multiple Analysis Range for the control group brackets and brackets immersed in tooth paste at three intervals.

\begin{tabular}{|c|c|c|c|c|c|c|}
\hline Variable & Period* & Mean & \pm SD & F-value & Sig. & $\begin{array}{l}\text { Duncan's } \\
\text { group }\end{array}$ \\
\hline \multirow{4}{*}{$\begin{array}{l}\text { Slot width } \\
\quad(\mathrm{mm})\end{array}$} & 0 & 0.46 & 0.000 & \multirow{4}{*}{0.000} & \multirow{4}{*}{1.000} & $\mathrm{~A}$ \\
\hline & 1 & 0.46 & 0.000 & & & A \\
\hline & 2 & 0.46 & 0.000 & & & A \\
\hline & 3 & 0.46 & 0.000 & & & A \\
\hline \multirow{4}{*}{$\begin{array}{l}\text { Slot depth } \\
\quad(\mathbf{m m})\end{array}$} & 0 & 0.76 & 0.000 & \multirow{4}{*}{0.000} & \multirow{4}{*}{1.000} & $\mathrm{~A}$ \\
\hline & 1 & 0.76 & 0.000 & & & $\mathrm{~A}$ \\
\hline & 2 & 0.76 & 0.000 & & & $\mathrm{~A}$ \\
\hline & 3 & 0.76 & 0.000 & & & $\mathrm{~A}$ \\
\hline \multirow{4}{*}{$\begin{array}{l}\text { Interwing gap } \\
\quad(\mathbf{m m})\end{array}$} & 0 & 1.26 & 0.000 & \multirow{4}{*}{0.000} & \multirow{4}{*}{1.000} & $\mathrm{~A}$ \\
\hline & 1 & 1.26 & 0.000 & & & A \\
\hline & 2 & 1.26 & 0.000 & & & A \\
\hline & 3 & 1.26 & 0.000 & & & A \\
\hline \multirow{4}{*}{$\begin{array}{l}\text { Bracket base } \\
\text { length }(\mathbf{m m})\end{array}$} & 0 & 2.79 & 0.000 & \multirow{4}{*}{10.69} & \multirow{4}{*}{$0.000 * *$} & $\mathbf{A}$ \\
\hline & 1 & 2.81 & 0.006 & & & B \\
\hline & 2 & 2.82 & 0.018 & & & B \\
\hline & 3 & 2.79 & 0.024 & & & A \\
\hline \multirow{4}{*}{$\begin{array}{c}\text { Bracket base } \\
\text { width }(\mathbf{m m})\end{array}$} & 0 & 3.76 & 0.000 & \multirow{4}{*}{0.859} & \multirow{4}{*}{0.471} & $\mathrm{~A}$ \\
\hline & 1 & 3.74 & 0.022 & & & A \\
\hline & 2 & 3.66 & 0.312 & & & A \\
\hline & 3 & 3.76 & 0.024 & & & A \\
\hline \multirow{4}{*}{$\begin{array}{l}\text { Wing length } \\
\text { (mm) }\end{array}$} & 0 & 3.01 & 0.000 & \multirow{4}{*}{150.54} & \multirow{4}{*}{$0.000 * *$} & A \\
\hline & 1 & 3.60 & 0.143 & & & B \\
\hline & 2 & 3.04 & 0.034 & & & A \\
\hline & 3 & 3.03 & 0.018 & & & A \\
\hline \multirow{4}{*}{$\begin{array}{l}\text { Wing width } \\
\text { (mm) }\end{array}$} & 0 & 3.65 & 0.000 & \multirow{4}{*}{307.50} & \multirow{4}{*}{$0.000 * *$} & B \\
\hline & 1 & 3.04 & 0.086 & & & $\mathbf{A}$ \\
\hline & 2 & 3.63 & 0.039 & & & B \\
\hline & 3 & 3.60 & 0.046 & & & B \\
\hline \multirow{4}{*}{$\begin{array}{l}\text { Bracket base } \\
\text { angle (in de- } \\
\text { gree) }\end{array}$} & 0 & 110.00 & 0.000 & \multirow{4}{*}{0.000} & \multirow{4}{*}{1.000} & $\mathrm{~A}$ \\
\hline & 1 & 110.00 & 0.000 & & & $\mathrm{~A}$ \\
\hline & 2 & 110.00 & 0.000 & & & $\mathrm{~A}$ \\
\hline & 3 & 110.00 & 0.000 & & & $\mathrm{~A}$ \\
\hline \multirow{4}{*}{$\begin{array}{l}\text { Labiolingual } \\
\text { angle (in de- } \\
\text { gree) }\end{array}$} & 0 & 90.00 & 0.000 & \multirow{4}{*}{0.000} & \multirow{4}{*}{1.000} & $\mathrm{~A}$ \\
\hline & 1 & 90.00 & 0.000 & & & $\mathrm{~A}$ \\
\hline & 2 & 90.00 & 0.000 & & & A \\
\hline & 3 & 90.00 & 0.000 & & & A \\
\hline
\end{tabular}

*0 control group (10 brackets), 1 first day in mouth wash, 2 two weeks in mouth wash, $\mathbf{3}$ one month in mouth wash (10 brackets for each period). ** Significant at $p \leq 0.05 ; \mathrm{SD}=$ Standard deviation.

\section{DISCUSSION}

The brackets parameters (slot width and depth, interwing gap, bracket base width, bracket base angle and labiolingual angle) of the brackets immersed in mouth wash and the tooth paste showed no significant difference as compared with the control group (Tables 1 and 2 ), this could be attributed to that the amount of metal ions release did not reach the significant level, and this comes in agreement with Kerosuo et al., Lin et al., and Von Fraunhofer ${ }^{(15-17)}$ who reported that corrosion occurs in clinical situation is not always possible to be registered.

The significant increase in the mean value of the bracket base length than the control group of the bracket group immersed in mouth wash during the first day of immersion indicated that the mouth wash has corrosion effect on the bracket base length and add oxidation layer this 
comes in agreement with Oshida et al., ${ }^{(18)}$. Then the length decrease significantly at the two week as compared with control, this could be due to that the oxidation layer was removed. While the length increased significantly at the four weeks of immersion as compared with the two week of immersion could be due to reoxidation of the length of bracket base length.

The significant increase of bracket base length for the bracket group immersed in tooth paste at one day and two weeks as compared with control group could be due to addition of oxidation layer this coincides with Poljak-guberina ${ }^{(19)}$ and the significantly decrease in length at four weeks as compared with those immersed at one day and two weeks could be due to the removal process of the oxidation layer.

The significant increase in wing length of the bracket group immersed in tooth paste at one day as compared with the control group explains the formation of oxidation layer, and the significant decrease at the immersion periods of two weeks and four weeks as compared with one day immersion may be due to the process of removal of the oxidation layer. Tooth paste which contains sodium fluoride creates a good electrolytic medium for the corrosion process to proceed. The significant decrease in wing width for the bracket group immersed in tooth paste at the one day as compared with control group disclosed the occurrence of the corrosion process during the first day of immersion. This finding in agreement with Sultan ${ }^{(20)}$.

\section{CONCLUSIONS}

Chlorhexidine mouth wash and tooth paste produce corrosion of the stainless steel brackets to the degree that cause no significant changes in the bracket dimensions except for the bracket base length of the brackets immersed in mouth wash, and the bracket base length, wing length and wing width for the brackets immersed in tooth paste.

\section{REFERENCES}

1. Ireland AJ, McDonald F. The orthodontic patient: treatment and biomechanics. $1^{\text {st }}$ ed. Oxford University Press. 2003, Pp:
181-298.

2. Eliades T, Zinelis S, Eliades G, Athanasion AE. Nickel content of as- received, retrieved and recycled stainless steel brackets. Am J Orthod Dentofacial Orthop. 2002; 122: 217-220.

3. Gursoy S, Acar AG, Seen C. Comparison of metal release from new and recycled bracket - arch wire combinations. Angle Orthod. 2004; 75(1): 92-94.

4. Cash AC, Good SA, Curtis RV, McDonald F. An evaluation of slot size in orthodontic brackets-Are standards as expected? Angle Orthod. 2003; 74(4): 450-453.

5. Eliades $\mathrm{T}$, Athanasiou AE. In vivo aging of orthodontic alloys: implication for corrosion potential, nickel release, and biocompatibility. Angle Orthod. 2002; 72(3): 222-237.

6. Schiff N, Dalard F, Lissac M, Morgon L, Grosgogeat B. Corrosion resistance of three orthodontic brackets: A comparative study of three fluoride mouth wash. Europ J orthod. 2005; 26(6): 541-549.

7. Daskalogiannakis J. Glossary of orthodontics term. Quintessence publishing Co. Inc. 2000;s Pp: 36.

8. Costa MT, Lenza MA, Gosch CG, Costa I And Ribeiro-Dias F. In vitro evaluation of corrosion and cytotoxicity of orthodontic brackets. J Dent Res. 2007; 86(5): 441445.

9. Anandkumar B, Maruthamuthu S. Molecular identification and corrosion behavior of manganese oxidizers on orthodontic wires. Current science. 2008; 94(7, 10):

10. House K, Sernetz F, Dymock D, Sandy JR, Ireland AJ. Corrosion of orthodontic appliances-should we care? Am J Orthod Dentofacial Orthop. 2008; 133(4): 584592.

11.Faccioni F, Franceschetti P, Cerpelloni M, Fracasso ME. In vivo study of metal release from fixed orthodontic appliances and DNA damage in oral mucosa cells. Am J Orthod Dentofacial Orthop. 2003: 124(6): 687-694.

12. Eliades T, Bourauel C. Intra oral aging of orthodontic materials: the picture we miss and its clinical relevance. Am J Orthod Dentofacial Orthop. 2005; 127(4): 403412.

13.Demir A, Malkoc S, Sengun A, Koyuturk A, Sener Y. Effects of chlorhexidine and povidone-iodine mouth rinses on the bond 
strength of an orthodontic composite. Angle orthod. 2004; 75(3): 392-396.

14.Hassan $\mathrm{OH}$. Consequences of three different recycling methods on features of stainless steel and pure titanium brackets (an in vitro study). MSc thesis. College of Dentistry. University of Mosul. 2006.

15. Kerosuo H, Moe G, Kleven E. In vitro release of nickel and chromium from different types of simulated orthodontic appliances. Angle orthod. 1995; 56(2): 111116.

16.Lin M, Lin S, Lee T, Huang H. Surface analysis and corrosion resistance of different stainless steel orthodontic brackets in artificial saliva. Angle orthod. 2005; 76(2): 322-329.
17.Von Fraunhofer JA. Corrosion of orthodontic devices. Semin Orthod.1997; 3(3): 198-205.

18. Oshida Y, Sachdeva RC, Miyazaki S. Microanalytical characterization and surface modification of nickel titanium orthodontic arch wires. Biomed mater engineer. 1992; 2(2): 51-69.

19.Poljak-guberina R, Kenezovic-Zlataric D, Katunaric M. Dental alloys and corrosion resistance. Acta stomat croat. 2002; 36: 447-450.

20.Sultan ZA. Measurements of depth and number of corrosion pits in some types of orthodontic wires (An in vitro study). MSc Thesis. College of Dentistry. University of Mosul. 2008. 